\title{
Escola de Enfermagem da Universidade de São Paulo: vestígios da história da profissionalização da Enfermagem no Brasil
}

Escuela de Enfermería de la Universidad de São Paulo: rastros de la historia de la profesionalización de la Enfermería en Brasil

\section{School of Nursing, University of São Paulo: traces the history of the professionalization of nursing in Brazil}

Genival Fernandes de Freitas ${ }^{1}$, Bárbara Barrionuevo Bonini ${ }^{2}$, Elaine Corrêa da Silva ${ }^{3}$,

Thaís Araújo da Silva ${ }^{4}$, Fabíola de Campos Braga Mattozinho ${ }^{5}$

${ }^{1}$ Livre Docente, Departamento de Orientação Profissional da Escola de Enfermagem da USP. Líder do Grupo de Pesquisa

História e Legislação da Enfermagem (EEUSP). São Paulo - Brasil.

${ }^{2}$ Enfermeira, Mestre e Doutora do Programa de Pós-Graduação em Gerenciamento em Enfermagem da EEUSP.

${ }^{3}$ Enfermeira. Doutoranda do Programa de Pós-Graduação em Gerenciamento em Enfermagem da EEUSP.

${ }^{4}$ Enfermeira. Mestranda em História e Legislação (EEUSP).

${ }^{5}$ Enfermeira. Mestranda em Ética e Legislação (EEUSP).

Cómo citar este artículo en edición digital: Freitas, G.F., Bonini. B.B., Silva, E.C., Araújo, T.A, Mattozinho, F.C.B. (2016). Escuela de Enfermería de la Universidad de São Paulo: rastros de la historia de la profesionalización de la Enfermería en Brasil. Cultura de los Cuidados (Edición digital), 20( 46). Disponible en: < http://dx.doi.org/10.14198/cuid.2016.46.07>

Correspondencia: Genival Fernandes de Freitas. Rua Cajaíba, 1130 - CEP 05025-001 - São Paulo - Brasil.

Correo electrónico: genivalf@usp.br

Recibido: 05/19//2015; Aceptado: 20/07/2016



\section{ABSTRACT}

This paper aims to describe and analyze the contributions of the School of Nursing, University of São Paulo (EEUSP) in the construc- tion and consolidation of professional nursing in Brazil, since its inception in the early 1940s. This is a socio-historical study on the legacy of the pioneering leaders of Brazilian nursing (Edith de Magalhães Fraenkel and Maria Rosa Sousa Pinheiro) and the examination of the latest contributions from other directors of EEUSP, with emphasis on the following themes: building of professional nursing, consolidation and strengthening of professional nursing education and nursing practices in Brazil. It sas outlined an itinerary of Brazilian nursing through the history of the professional life of Edith de Magalhães Fraenkel and Maria Rosa Sousa Pinheiro, first and second directors of EEUSP. The contributions of EEUSP for the professionalization of Brazilian nursing were numerous, especially in nursing education at the undergraduate and graduate levels and to 
strengthening of nursing as a socially and politically relevant practice in the national and international scenes through research and academic production.

Keywords: Nursing, Nursing history; Professionalization, Nursing Education.

\section{RESUMEN}

Este trabajo tiene como objetivo describir y analizar las aportaciones de la Escuela de Enfermería de la Universidad de São Paulo (EEUSP) para la construcción y consolidación de la enfermería profesional en Brasil desde sus inicios en la década de 1940. Se desarrolló un estudio socio-histórico sobre el legado de los líderes pioneros de la enfermería brasileña (Edith Magallanes Fraenkel y Maria Rosa Sousa Pinheiro) y sobre el examen de las últimas aportaciones de otros directores de la misma Escuela, con énfasis en las siguientes categorías temáticas: la construcción profesional, consolidación y el fortalecimiento de la educación profesional de enfermería y la práctica de enfermería en Brasil. Fue trazado un itinerario de la enfermería brasileña a través de la restauración de la historia de la vida profesional de Edith Magallanes, primer director de la EEUSP y gestión de Maria Rosa de Sousa Pinheiro, segundo director de la misma institución. Las contribuciones de EEUSP para la profesionalización de la enfermería brasileña fueron numerosas, especialmente en la educación de enfermería en los niveles de pregrado y postgrado y para fortalecer la enfermería como práctica social y políticamente relevante en el panorama nacional e internacional a través de la investigación, producción y difusión de conocimientos en la área de salud y de enfermería.

Palabras clave: Enfermería, História de la enfermería, Profesionalización.

\section{RESUMO}

Este trabalho tem por objetivo descrever e analisar as contribuições da Escola de Enfermagem da Universidade de São Paulo (EEUSP) para a construção e consolidação da enfermagem profissional no Brasil desde sua origem nos primórdios da década de 1940. Desenvolveu-se um estudo histórico-social a partir do legado das líderes pioneiras da enfermagem brasileira (Edith de Magalhães Fraenkel e Maria Rosa Sousa Pinheiro) e do exame das contribuições mais recentes de outros diretores da EEUSP, com ênfase nas seguintes categorias temáticas: construção da enfermagem profissional, consolidação da enfermagem profissional e fortalecimento do ensino e do exercício da enfermagem no Brasil. Delineou-se um itinerário da enfermagem brasileira por meio do resgate da história de vida profissional de Edith Magalhães, primeira diretora da EEUSP e da gestão de Maria Rosa de Sousa Pinheiro, segunda diretora da EEUSP. As contribuições da EEUSP para a profissionalização da enfermagem brasileira foram inúmeras com destaque para a formação do enfermeiro em nível de graduação e pós-graduação e para o fortalecimento da enfermagem como prática social e politicamente relevante nos cenários nacional e internacional por meio de pesquisas e da produção acadêmica dos docentes.

Palavras chave: Enfermagem, História da enfermagem; Profissionalização.

\section{NOTAS INTRODUTÓRIAS}

Escrever as contribuições da Escola de Enfermagem da Universidade de São Paulo (EEUSP) para o processo de profissionalização da enfermagem no Brasil, requer a priori, um revisitar o seu passado e seus atores. Tal empreendimento é desafiador, se considerar- 
mos as sínteses históricas feitas dantes pela Profa Maria Rosa de Sousa Pinheiro, por ocasião do Jubileu de Prata da Escola, em 1967 e, posteriormente, pela Profa Amália Corrêa de Carvalho, que em sua obra "Escola de Enfermagem da Universidade de São Paulo. Resumo histórico: 1942 -1980", acentuou não só o lugar social dessa instituição, mas os desafios e legados às futuras gerações de profissionais.

Nesse sentido, a historiografia nos revela alguns antecedentes à criação da EEUSP dignos de registros a fim de se demonstrar algumas iniciativas pioneiras na área da saúde no Estado de São Paulo:

A existência de um Curso de obstetrícia, que funcionou na Maternidade de São Paulo até 1911, quando foi extinto. Em março de 1912, foi criada a Escola de Parteiras de São Paulo, que também passou a funcionar naquela Maternidade e em 1931, passou a se chamar Escola de Obstetrícia e Enfermagem Especializada. Em 1939, foi anexada à Cadeira de Clínica Obstétrica da Faculdade de Medicina da USP, com o nome de "Curso de Enfermagem Obstétrica”. Em 1944, mudou-se da Maternidade de São Paulo para o Hospital das Clínicas e em 1962 passou a integrar a USP, com o nome de Escola de Obstetrícia anexa ao Departamento de Obstetrícia e Ginecologia da Faculdade de Medicina da USP. Em 1971, foi integrada à EEUSP pela Portaria GR n. 1.398/71 (Carvalho, 1980, p. 17).

Presume-se que o curso de enfermagem da Escola de Enfermeiras do Hospital Samaritano, na cidade de São Paulo, tenha se iniciado em 1900 ou 1901, graças à contratação, pela direção daquele hospital na época, de cinco enfermeiras inglesas que chegaram no decorrer do ano de 1894. Era uma escola tipicamente inglesa, pois não havia no Brasil, na área do ensino de enfermagem, nada que pudesse servir de para- digma ou modelo. O Decreto Federal n. 791, de 27/09/1890, estabeleceu currículo e critério de seleção de candidatas muito abaixo das exigências prescritas pelas escolas de enfermagem no Sistema Nightingale, o qual previa, entre outras exigências, que o curso deveria ser dirigido por enfermeiras bem como o ensino teórico e prático ministrado por enfermeiras e, eventualmente, por médicos. A referida Escola, não tendo interesse em se ajustar às prescrições legais da Lei n. 775, de 6/12/1949, foi transformada, em 1950, em curso de auxiliar de enfermagem, e mais tarde (em 1959) foi denominada Escola de Enfermagem "Job Lane", tendo encerrado suas atividades em 1970.

A Escola de Enfermeiras do Hospital São Paulo foi autorizada a funcionar em outubro de 1938 e em princípios de 1939 deu início às suas atividades.

A formação de enfermeiras pela Escola de Enfermagem da Cruz Vermelha Brasileira, filial do Estado de São Paulo; também antecedeu à EEUSP, pois em 1940, a exemplo da filial do Rio de Janeiro, foi instituído o curso de enfermagem, com a denominação de Curso Profissional de Enfermeiras daquela instituição, que perdurou até 1963.

O presente trabalho tem como objetivo descrever e analisar as contribuições da Escola de Enfermagem da USP para a construção e consolidação da enfermagem profissional no Brasil, desde sua origem nos primórdios da década de 1940 até os dias presentes.

\section{METODOLOGIA}

A História da Enfermagem tem relevância fundamentada na formação ética e política do enfermeiro, capacitando-o a enxergar o passado da profissão, mas também essa disciplina é capaz de propor ações no presente para a (re) invenção da identidade coletiva. 
O presente estudo norteou-se pelo problema: quais foram as contribuições da Escola de Enfermagem da USP para a profissionalização da Enfermagem brasileira a partir da década de 1940 ?

Para tanto, optou-se pelo método indiciário da pesquisa histórica, o qual pressupõe um minucioso conhecimento de uma realidade social para descobrir vestígios ou sinais não diretamente experimentáveis pelo observador. Nesse sentido, o conhecimento histórico é indireto, indiciário e conjetural (Ginzburg, 1990). No objeto desta investigação, interessa-nos desvelar as contribuições não só das diretoras da Escola de Enfermagem da USP, mas de todos os agentes (professores, alunos, enfermeiros, etc) dessa instituição para plasmar a enfermagem como uma prática socialmente mais visível e reconhecida, mormente no cenário paulista, nas décadas de 1940 até os dias mais atuais.

As fontes do estudo foram compostas pelo acervo documental do Centro Histórico Cultural da Enfermagem Ibero-Americana, da Escola de Enfermagem da USP, que contempla documentos referentes à atuação dessa Escola no cenário da profissionalização da Enfermagem em diferentes décadas, a partir de 1940, quando foi criada.

Após a seleção da documentação, procedeu-se à análise de cada documento no que tange à crítica interna e externa, seguindo os critérios propostos por Silva Junior (2011, pp. 357-60). Assim, cada documento sofreu questionamentos, abstraindo-se dele fragmentos da história da enfermagem que se faziam presentes nos discursos.

Este é, portanto, um estudo histórico-social embasado em fontes documentais do CHCEIA, tendo como objeto as contribuições da Escola de Enfermagem da USP para a profissionalização da Enfermagem brasileira. Com isso, os achados foram organizados por categorias temáticas e serão apresentados da seguinte maneira: Legados de Edith de Magalhães Fraenkel à consolidação da enfermagem profissional no Brasil; Contribuições de $\mathrm{Ma}$ ria Rosa Sousa Pinheiro no fortalecimento do ensino e do exercício da enfermagem no país e Contribuições mais recentes e atuação de outros diretores da Escola de Enfermagem da USP rumo à construção da enfermagem profissional no Brasil.

\section{RESULTADOS E DISCUSSÃO}

As primeiras décadas, após a criação da Escola de Enfermagem da USP, foram marcadas pela firme atuação das diretoras, as professoras Edith de M. Fraenkel e Maria Rosa de S. Pinheiro, que além de defensoras convictas da enfermagem como uma prática social necessária, enfrentaram desafios para manutenção, expansão e visibilidade social da Escola.

No que tange aos legados de Edith de Magalhães Fraenkel à consolidação da enfermagem profissional no Brasil, vê-se que a história da criação da EEUSP nos remetem ao interesse da Fundação Rockefeller na futura Escola de Enfermagem de São Paulo (atualmente EEUSP), o que pode ser avaliado pela troca de correspondências entre os diversos diretores do conselho sanitário internacional sediado no Rio de Janeiro, nas décadas de 1930 e 40 e as personalidades de São Paulo, principalmente os diretores da Faculdade de Medicina (criada em 1913) e do Instituto de Higiene 1918 (Carvalho, 1980) de São Paulo. Assim, em 1940, a Fundação Rockefeller enviou a São Paulo a chefe da Seção de Enfermagem da Fundação, Miss Mary E. Tenant, com o escopo de persuadir as autoridades a observarem o convênio firmado em 1925 e do acordo feito 
em 1938 no sentido de concretizarem a ideia da criação da Escola de Enfermagem da USP.

Um ano antes da criação da EEUSP, Edith de Magalhães Fraenkel assumiu as atividades de planejamento da nova Escola e assumiu como primeira diretora da Escola. O Decreto-Lei Estadual n. 13.040, de 31 de outubro de 1942 oficializou a criação da EEUSP.

No ano de 1940, Maria Rosa S. Pinheiro e Zilda de Almeida Carvalho, ambas educadoras sanitárias, foram enviadas à Universidade de Toronto, no Canadá, para fazerem o curso de enfermagem. Edith Fraenkel já tinha se graduado em enfermagem em 1926, na Universi-

\section{Imagen 1}

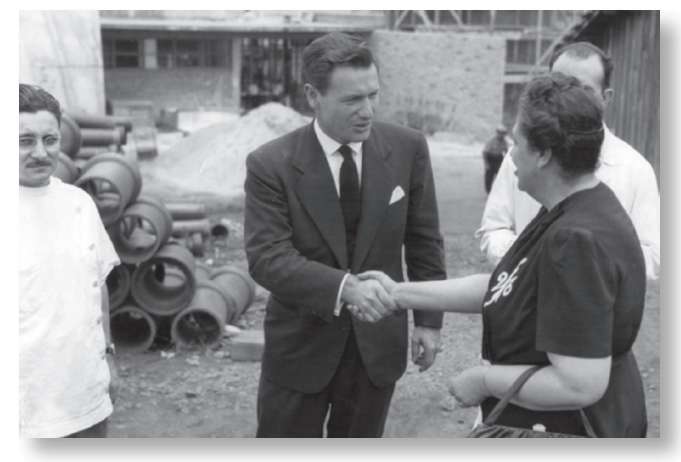

Acervo do Centro Histórico Cultural da Enfermagem Ibero Americana, da EEUSP. Nelson Rockefeller com Edith de Magalhães Fraenkel no canteiro de obras do edifício que abrigaria as instalações da Escola de Enfermagem de São Paulo, atualmente, EEUSP.

dade da Pennsylvania, nos EUA.

É inegável a competência e fidedignidade aos acontecimentos narrados pela Dra Amália Corrêa de Carvalho, em sua memorável obra sobre a "Escola de Enfermagem da USP. Resumo histórico - 1942-1980". Nesta, a autora trata de vários temas afetos à trajetória histórica da EEUSP, desde o período da sua instala- ção ao pleno funcionamento e à sua expansão rumo ao Brasil e à América do Sul (Oguisso, Freitas, Takashi, 2013).

A presença da enfermeira e consultora americana Ella Hasenjaeger na EEUSP, no período de 1944 a 1951, foi marcante, pois ela exerceu atividades docentes no ensino de enfermagem psiquiátrica e de doenças transmissíveis, além do seu envolvimento nas atividades do $1^{\circ}$ Congresso Nacional de Enfermagem, em 1947 e secretariou a Aben, seção São Paulo, que estava iniciando como seção autônoma. Além disso, ela teria afirmado que essa Escola teria se tornado uma das melhores escolas de enfermagem do país e mesmo dos Estados Unidos (Carvalho, 1980).

\section{Imagen 2}

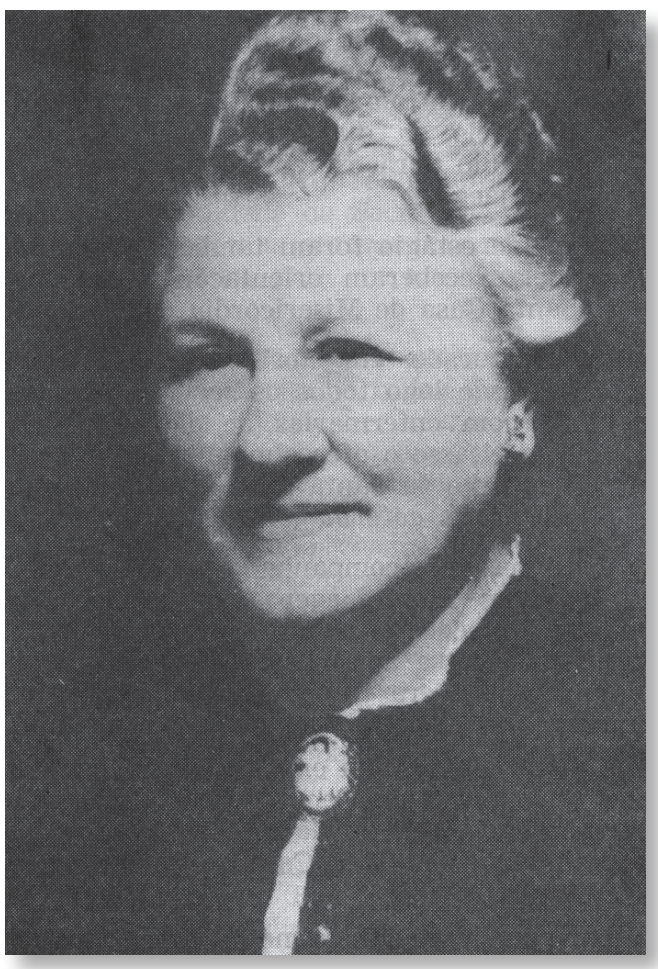

Ella Hasenjaeger - Carvalho AC. Escola de Enfermagem da Universidade de São Paulo. Resumo histórico - 1942 1980. São Paulo, p. 47. 
No período de 1946 a 1950, a autora destaca a formatura da primeira turma (classe de 1946). Nesse período, Edith continuava dirigindo a EEUSP e também foi reeleita presidente da Associação Brasileira de Enfermagem (Aben) e integrou o Conselho Diretor do Conselho Internacional de Enfermeiras (CIE), além de atuar junto à Federação Interamerica-

\section{Imagen 3}

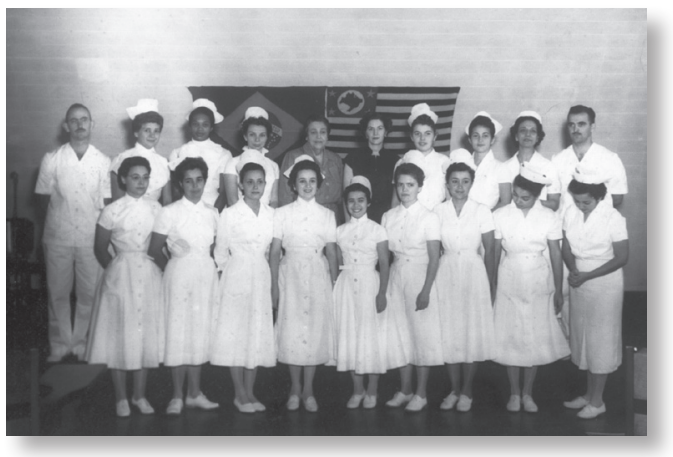

Acervo do Centro Histórico Cultural da Enfermagem Ibero Americana, da EEUSP Turma de 1955.

na de Enfermagem.

Breves passagens sobre essas líderes pioneiras da enfermagem brasileira (Edith Fraenkel e Maria Rosa) são necessárias para o registro da história e da memória de quem teve o privilégio de conhecê-las pessoalmente ou mesmo de conviver com elas:

Edith de Magalhães Fraenkel é considerada a "pioneira das pioneiras", talvez por ter sido a primeira enfermeira brasileira diplomada nos EUA, a primeira diretora da EEUSP, a primeira presidente da Associação Brasileira de Enfermeiras Diplomadas, atualmente Associação Brasileira de Enfermagem, criada em 1926, entre outras iniciativas pioneiras suas, à época da sua gestão à frente da Escola ou da Associação.
Ela nasceu no Rio de Janeiro em 09/05/1889. Era neta de Benjamim Constant Botelho de Magalhães. Em 1920, concluiu o curso de Visitadora na Inspetoria de Tuberculose do Departamento Nacional de Saúde Pública (DNSP). Diplomou-se no curso de enfermagem no "Philadelphia General Hospital", nos EUA (Secaf, Costa, 2007; p. 22).

Ao retornar ao Brasil, lecionou na Escola de Enfermeiras do DNSP, onde permaneceu de 1925 a 1927 como instrutora e coordenadora de ensino. Em 1926, foi uma das principais artífices na criação da Associação Brasileira de Enfermagem, sendo sua primeira presidenta, de 1927 a 1938 (Oguisso, Freitas, Takashi, 2013).

Em novembro de 1941, Edith foi comissionada pelo Governo Federal junto à Universidade de São Paulo e no final do ano seguinte, foi nomeada pelo Governo de São Paulo como Diretora da Escola de Enfermagem da Universidade de São Paulo, criada através do decreto estadual n. 13.040 de 31 de outubro de 1942 (Carvalho, 1992; Oguisso, Freitas, Takashi, 2013).

De 1938 a 1946, Edith foi membro da Divisão de Educação da Aben, que posteriormente se chamou Comissão de Educação. Em 1949, colaborou na reorganização da Escola de Enfermagem da Universidade Federal da Bahia. Realizou, em Petrópolis (RJ), o XI Congresso do Conselho Internacional de Enfermeiras, em 1953. No ano seguinte, instalou o curso de auxiliares de Enfermagem na Escola de Enfermagem da USP. Em 1956, coordenou o Departamento de Ensino da Escola de Enfermagem Alfredo Pinto até o ano de 1961 (Arone, Ferreira, Canavezzi, Chaccur, 2001).

A coordenação do $1^{\circ}$ Congresso Nacional de Enfermeiras, em território de liderança de Edith, nos parece que explicita uma impor- 
tante vitória desta enfermeira, visto que nas reuniões de diretoras ela questionava muito a prerrogativa de somente uma escola ser responsável pela avaliação da implantação de escolas e, ao mesmo tempo o modelo a ser seguido (Mancia, Padilha, 2006). A partir da Lei $775 / 49$, tal quesito deixa de existir, passando essa função para o Ministério da Educação (Oguisso, Freitas, Takashi, 2013).

\section{Imagen 4}



Acervo do Centro Histórico Cultural da Enfermagem Ibero Americana, da EEUSP - $1^{a}$ Turma da EEUSP - 1946.

Em 1957, a Aben instituiu o prêmio Edith Magalhães Fraenkel, que é patrocinado pela Escola de Enfermagem da USP e diz respeito aos melhores trabalhos relativos à pesquisa em enfermagem apresentados no Congresso Brasileiro de Enfermagem (Aben, 1959).

O resgate da história de vida profissional de Edith Magalhães permite-nos estabelecer um itinerário da enfermagem brasileira, além de reconhecer a centralidade desta personagem na enunciação de um discurso da profissão da enfermagem. Era vista como "enérgica, de poucas palavras, perseverante na busca de seus objetivos e, com firmeza, defendia seus pontos de vista”. As referidas autoras intitulam-na como "pioneira das pioneiras" (Secaf, Costa, 2007, p.30). Edith faleceu em 5 de abril 1969.
A segunda diretora da EEUSP foi Maria Rosa de Sousa Pinheiro. Ela teve o período mais longo até hoje na liderança da Escola, mas também grande influência na condução das entidades de classe da enfermagem brasileira, como a Associação Brasileira de Enfermagem e os Conselhos de fiscalização, sendo uma das suas mentoras e condutoras.

\section{Imagen 5}



Maria Rosa de Sousa Pinheiro: Acervo do Centro Histórico Cultural da Enfermagem Ibero Americana, da EEUSP.

Maria Rosa nasceu em Araraquara em 14 de dezembro de 1908. Ainda menina veio morar na Capital e estudou na Escola Normal da Praça da República. Em 1930 fez o Curso de Educadora Sanitária no Instituto de Higiene, onde conheceu o Dr. Geraldo de Paula Souza. No ano de 1937, bacharelou-se em Letras Estrangeiras. Depois fez o curso superior de enfermagem, na Universidade de Toronto, no Canadá, de 1940 a 43. Em 1947, fez o Master of Arts, na Universidade Columbia - Teachers College - New York. 
Maria Rosa nasceu em Araraquara em 14 de dezembro de 1908. Ainda menina veio morar na Capital e estudou na Escola Normal da Praça da República. Em 1930 fez o Curso de Educadora Sanitária no Instituto de Higiene, onde conheceu o Dr. Geraldo de Paula Souza. No ano de 1937, bacharelou-se em Letras Estrangeiras. Depois fez o curso superior de enfermagem, na Universidade de Toronto, no Canadá, de 1940 a 43. Em 1947, fez o Master of Arts, na Universidade Columbia - Teachers College - New York.

\section{Imagen 6}



Acervo do Centro Histórico Cultural da Enfermagem Ibero Americana, da EEUSP. Maria Rosa Sousa Pinheiro.

Maria Rosa ocupou cargos no Serviço Especial de Saúde Pública - SESP. Foi educadora chefe, de 1939 a 1940. Diretora da Divisão de Enfermagem, de 1951 a 55 e também participou da direção da Escola de Enfermagem de São Paulo da Faculdade de Medicina da Universidade de São Paulo - EEFMUSP, desde o início. Vale lembrar que a Escola de Enfermagem da USP era denominada Escola de Enfermagem da Faculdade de Medicina da USP (EEFMUSP), desde a sua criação, porém tornou-se unidade autônoma, a partir de 1963, com a desanexação, em consequência da Lei 775/49 que obrigava as Escolas de Enfermagem a terem congregação própria.

Foi vice-diretora de 1944 a 1951 da EEUSP e vice-diretora no exercício do cargo de diretora de agosto de 1955 (quando da saída da Dna Edith Fraenkel da direção da Escola) a dezembro de 1956. Depois foi nomeada Diretora pelo Governador Jânio Quadros, a partir de janeiro de 1957, tendo permanecido no cargo até outubro de 1978, quando se aposentou.

À época da gestão Maria Rosa na diretoria da EEUSP desencadeou-se o processo de desanexação da Faculdade de Medicina da USP, que se concretizou em 1963. A participação em eventos nacionais e internacionais como o I Congresso Nacional de Enfermagem (1947) e o X Congresso Quadrienal do CIE (1953). A Presidência da Associação Brasileira de Enfermagem, de 1954 a 58 e a participação no planejamento do Levantamento de Recursos e Necessidades da Enfermagem no Brasil 1956-1958, como sendo uma pesquisa pioneira no país sobre as reais necessidades de pessoal na enfermagem. Na verdade, essa foi, certamente, a primeira pesquisa científica de Enfermagem no Brasil, que agregou uma equipe de 79 pessoas entre técnicos, estatísticos, pesquisadores e enfermeiras e foi patrocinada pela Fundação Rockefeller (70 mil dólares, na época), e contou com a parceria da OMS, IBGE, Ministério da Saúde, MEC e OPAS, além obviamente da principal entidade representativa do coletivo da enfermagem no Brasil, a Associação Brasileira de Enfermagem, a Aben. 
Ainda sobre o passado, no tempo de Da Maria Rosa, vale recordar eventos que aconteceram na EEUSP, por exemplo a reunião do Conselho de Representantes Nacionais (CRN) do Conselho Internacional de Enfermeiras (CIE) em julho de 1953, durante o qual foi aprovado o primeiro Código de ética da Enfermagem; o Primeiro Congresso Brasileiro (Nacional) de enfermagem, em 1947, além do $3^{\circ}$ Congresso de Educação de Enfermagem, todos estes eventos aconteceram no campo da EEUSP.

Seu papel de liderança à frente do Conselho Federal de Enfermagem - Cofen, foi marcante, inclusive rumo à aprovação da Lei 5905/73, que criou o Sistema COFEN/COREN, que culminou, ato contínuo, com a instalação COFEN-1975pelo Ministro do Trabalho da época, Sr. Arnaldo Prieto. A eleição pelos pares de Da. Maria Rosa como Primeira Presidente do COFEN ocorreu em 1975-77.

Maria Rosa teve a sensibilidade de perceber a necessidade de preparar docentes para escolas de enfermagem do Brasil e também formar administradoras de unidades de enfermagem hospitalar. Com isso, na sua gestão foram criados os dois primeiros cursos de pós-graduação em enfermagem, em 1959: um deles de Pedagogia e Didática aplicada à Enfermagem e de Administração de Unidade de Enfermagem, em nível lato sensu. Uma longa trajetória rumo à construção de uma massa crítica docente a fim de concretizar a pós-graduação stricto sensu, a qual de fato se concretizou com o Curso de Mestrado, em 1973, na área de concentração de Fundamentos de Enfermagem.

Maria Rosa passou 23 anos no cargo de Diretora da EEUSP, com uma gestão marcada por inúmeras inovações e conquistas, tanto no ensino como na constituição da enfermagem como profissão (Fonseca, Forcella, 2012). Am- pliou o prédio, introduziu o exame de seleção das candidatas ao curso (precursor do vestibular) e um programa de orientação às alunas recém-admitidas; conseguiu a contratação de professoras na proporção de uma para cada grupo de 10 alunas; introduziu o sistema de avaliação do curso pelas próprias estudantes ao término de cada disciplina, como maneira de provocar a sua participação no planejamento curricular (Fonseca, Forcella, 2012).

Depois de muito batalhar, finalmente, em 1958, testemunhou a criação oficial do Curso Superior de Enfermagem, sendo obrigatório para matrícula o certificado de conclusão do curso secundário. Era a entrada da Enfermagem no Olympo Universitário, depois de um longo período de luta para que se constituísse como profissão de nível superior. No ano seguinte, em 1959, instalou os dois primeiros cursos de pós-graduação daquela Escola, destinados ao preparo de docentes e de administradoras de unidades de enfermagem (Fonseca, Forcella, 2012).

$\mathrm{Na}$ Ata da 545 a Sessão do Conselho Universitário da Universidade de São Paulo: “Aos três dias do mês de fevereiro de mil novecentos e sessenta e quatro, às 14 horas, reuniu-se o Conselho Universitário, em sessão ordinária, na Reitoria da Universidade de São Paulo, na Cidade Universitária 'Armando de Salles Oliveira', sob a presidência do Magnífico Reitor Luis Antonio da Gama e Silva (...). Expediente: O Reitor congratula-se com a presença de D. Maria Rosa Sousa Pinheiro, Diretora da Escola de Enfermagem de São Paulo, que toma assento no Conselho pela primeira vez, em razão da transformação da Escola em Estabelecimento de Ensino Superior, dizendo esperar a melhor colaboração. A Conselheira Maria Rosa Sousa Pinheiro agradece e promete colaboração (Ata do CO, 1964). 
Dona Maria Rosa participou intensa e constantemente das reuniões do Conselho Universitário da USP. Era a única mulher entre 30 conselheiros homens. Manteve se assim a até que a Profa. Dra. Glete de Alcântara, Diretora da Escola de Enfermagem de Ribeirão Preto, também passasse a compor o CO. Marcou presença e fez solicitações, a despeito da atitude marcadamente androcêntrica da mesa e do plenário. A aparente consideração para com elas nem sempre redundava em igualdade de oportunidades em relação aos homens. A praxe era conceder-lhes a palavra somente ao final da reunião ou mesmo na reunião seguinte. Isto ela nos contava sem fazer alarido, ressaltando que o que lhe garantia a participação era mais a insistência que o poder, visivelmente diferente dos homens (Fonseca, Forcella, 2012). Maria Rosa faleceu em 21 de junho de 2002 com 93 anos.

Depois que a Profa Maria Rosa se afastou, por motivo de aposentadoria, da direção da Escola de Enfermagem da USP, vê-se que houve um período seguinte de direção por profissionais formados em outras áreas do conhecimento. Assim, o médico Prof. Carlos da Silva Lacaz assumiu a direção da Escola, de 1978 a 82. Depois a Profa Dra Leda Ulson Matos (1982 a 86), graduada em Química, pelo Instituto de Química da USP. Cabe destacar que ela foi a primeira professora da Escola de Enfermagem da USP a fazer um Doutorado pela própria Escola, concluindo-o em 1971.

À medida que as enfermeiras foram se doutorando e atingindo o patamar mais elevado da carreira acadêmica (antiga cátedra), a liderança da EEUSP passou a ser das próprias enfermeiras. Assim, a Profa Dra Yoriko Kamiyama, que se graduou em enfermagem em 1963, fez seu doutorado em 1972 e tornou-se professora titular do Departamento de Enfer- magem Médico-Cirúrgica em 1981 e diretora da EEUSP, de 1986 a 89. Desse mesmo departamento, as Profas titulares, Dra Sonia Della Torre Salzano e Dra Tamara Iwanow Cianciarullo, dirigiram a EEUSP nos períodos de 1989 a 1991 e de 1991 a 95, respectivamente.

A Dra Paulina Kurcgant foi a Diretora de 1995 a 99. Ela se graduou, primeiramente, em Obstetrícia, depois em enfermagem, tendo feito seu doutorado em enfermagem em 1984 e atingido a titularidade acadêmica em 1995. Depois a Dra Emiko Yoshikawa Egry foi diretora dessa Escola de 1999 a 2003, seguida pela Dra Ana Maria Kazue Miyadahira (2003 2007), sendo substituída pela Dra Isília Aparecida Silva foi a Diretora de 2007 a 2011 e atualmente a Dra Diná de Almeida Lopes Monteiro da Cruz, cujo mandato deve finalizar no ano vindouro.

A Escola d Enfermagem da USP possui, atualmente, sete programas de pós-graduação, sendo eles: Programa de Pós-Graduação em Enfermagem (PPGE) - Mestrado e Doutorado; Programa de Pós-Graduação Interunidades em Enfermagem - EE/EERP - Doutorado; Programa de Pós-Graduação em Enfermagem na Saúde do Adulto - Mestrado e Doutorado; Programa de Pós-Graduação em Gerenciamento em Enfermagem (PPGEn) - Mestrado e Doutorado; Programa de Pós-Graduação Mestrado Profissional em Enfermagem na Atenção Primária em Saúde no Sistema Único de Saúde - Mestrado Profissional e Programa de Pós-Graduação Mestrado Profissional Interunidades em Formação Interdisciplinar em Saúde - Mestrado Profissional.

A EEUSP firmou compromissos para o desenvolvimento de um Programa de Doutorado Internacional (DINTER) com a Pontifícia Universidade Católica do Chile, além de outras parcerias para o Doutorado Interinstitucional 
(DINTER Nacional) com as Universidades Federal do Amapá, de Sergipe e do Amazonas.

Os programas de pós-graduação mencionados formaram, até a presente data (16 de abril de 2014), 1.134 mestres, 745 doutores, sendo 408 do Interunidades em Enfermagem.

Há um contingente de 17 professores titulares, 38 professores associados, 26 doutores e 1 assistente, que se vinculam a quatro Departamentos, responsáveis pelo ensino e pelas respectivas áreas de saber. A maioria desses docentes são líderes ou integram os 56 grupos de pesquisa da Escola, cadastrados no Conselho Nacional de Desenvolvimento Científico e Tecnológico (CNPq). A Escola conta, também, com pessoal administrativo dedicado e especializado que garante o suporte técnico aos docentes e estudantes dos diversos níveis de formação.

A EEUSP conferiu grau de bacharel em enfermagem a 3.368 enfermeiros, em 67 turmas de egressos, no período de 1946 a 2013. Para formar profissionais de enfermagem, a Escola dispõe de infraestrutura composta por laboratórios de enfermagem, de informática, de pesquisa experimental e de um centro histórico, além de disponibilizar de biblioteca própria e de parcerias com instituições congêneres para o ensino de ciências básicas da saúde e externamente, como cenários de práticas dos nossos estudantes, seja nas Unidades Básicas de Saúde ou em instituições de assistência em diferentes níveis de complexidade, nos setores público e privado. Para a consecução desse ensino, a Escola disponibiliza também de 18 enfermeiras contratadas como especialistas, 01 educador, 01 estatístico, 01 técnico na Seção de Apoio Laboratorial e 01 na Revista da EE.

A Escola possui Serviço de Biblioteca e Documentação que, certamente, detém o maior acervo impresso de enfermagem da
América Latina. Esse Serviço tem ampliado a atenção aos usuários em geral e também tem oferecido, periodicamente, oficinas de capacitação em levantamento de dados a estudantes da própria Escola. Em parceria com o Centro Histórico Cultural da Enfermagem Iberoamericana (CHCEIA), - que foi fundado em 1992, a Biblioteca está organizando o acervo específico sobre as obras da história da enfermagem existentes na Escola, e que inclui, também, classificação, higienização, restauração e organização arquivística que retratam a história e as contribuições dessa Escola para a construção social da enfermagem brasileira e das entidades de classe nessa profissão.

\section{À guisa de conclusão}

Por ocasião da comemoração do aniversário de 70 anos da fundação da EEUSP em 31 de outubro de 2012, realizou-se o III Encontro Internacional de Pesquisa em Enfermagem, como parte do corolário de ações reveladores da vocação dessa instituição para a pesquisa, o ensino e a extensão de serviços à coletividade social.

As contribuições da Escola de Enfermagem da USP à profissionalização da enfermagem brasileira foram inúmeras, por intermédio não somente de suas líderes e de suas diretoras, mas na atuação conjunta do corpo docente, discentes e dos funcionários dessa instituição. No rol dessas contribuições deve estar, certamente, presente a preocupação com a formação de recursos humanos qualificados para a saúde, tanto em nível de graduação quanto de pós-graduação.

O legado dessa Escola foi decisivo no fortalecimento da enfermagem como uma prática social e politicamente relevante nos cenários nacional e internacional, seja por meio das pesquisas, seja por meio da inserção dos 


\section{Cultura de las Cuidados}

docentes nas suas áreas de conhecimento e produção acadêmica, contribuindo para as práticas do cuidado das pessoas e da gestão em serviços de saúde.

\section{REFERÊNCIAS}

- Arone, E.M., \& Ferreira, E.T.R., Canavezzi, R., \& Chaccur, M.I.B. (2001). Associação Brasileira de Enfermagem -seção São Paulo, notas sobre as contribuições para a enfermagem brasileira. Rev Bras Enferm, 54(2), 364-81.

- Carvalho, A.C. (1992). Edith Magalhães Fraenkel. São Paulo: Escola de Enfermagem da USP;

- Carvalho, A.C. (1980). Escola de Enfermagem da USP. Resumo histórico: 1942-1980. São Paulo: Escola de Enfermagem da USP.

- Fonseca, R.M.G.S., \& Forcella, H.T. (2012). Maria Rosa de Sousa Pinheiro: uma (bela) mulher feita de tango, ousadia e enfermagem. História da Enfermagem - Revista Eletrônica (HERE), 3, 47-55.
- Ginzburg, C. (1990). Sinais: raízes de um paradigma indiciário. In Mitos, emblemas, sinais: Morfologia e História. $1^{\text {a }}$ reimpressão. São Paulo: Companhia das Letras.

- Mancia, J.R., \& Padilha, M.I.C.S. (2006). Trajetória de Edith Magalhães Fraenkel. Rev Bras Enferm, 59 (nº especial), 432-7.

- Oguisso, T., Freitas, G.F., \& Takashi, M.H. (2013). Edith de Magalhães Fraenkel: o maior vulto da enfermagem brasileira. Rev Esc Enferm USP, 47(5), 1227-34

- Pinheiro, M.R.S. (1967). Histórico da Escola de Enfermagem da USP. Rev. Esc. Enf. São Paulo, 1(1), 3-34.

- Secaf, V., \& Costa, H.C.B.V. (2007). Enfermeiras do Brasil. Histórias das Pioneiras. São Paulo: Ed. Martinari .Universidade de São Paulo.

- Silva Junior, O.C. (2011). Pesquisa documental. In T. Oguisso., P.F.S., Campos., \&Freitas, G.F. (Eds.), Pesquisa em história da enfermagem (pp.80-99) São Paulo: Editora Manole.



